\title{
Estudio de susceptibilidad in vitro en Haemophilus influenzae
}

\author{
OLIVIA TRUCCO A.
}

\section{In vitro SUSCEPTIBILITY TESTING OF Haemophilus influenzae}

The genus Haemophilus comprises a group of small, pleomorphic gram negative rods with fastidious growth requirements. $\boldsymbol{H}$. influenzae type $\boldsymbol{b}$ the most important, is a small gram negative coccobacillus that appears pleomorphic in clinical smears. It is a non motile bacteria, non spore-forming, facultative anaerobe, that requires two accessory factors $(X-V)$ for in vitro growth. Both factors are present within erythrocytes and are released by heat (chocolate agar). The main criterium for diagnosis of $\boldsymbol{H}$. influenzae infections is Gram stain and isolation of the organisms from the infected focus. Because $\boldsymbol{H}$. influenzae is very fastidious and dies quickly in clinical specimens at room temperature, samples should be planted immediately. They should be streaked directly on the surface of a chocolate agar and incubated aerobically in an atmosphere of $10 \% \mathrm{CO}_{2}$. The treatment of invasive $\boldsymbol{H}$. influenzae, infections specially meningitis, is a medical emergency, any unnecessary delay in starting treatment may make the difference between life and death, so the knowledge of antimicrobial susceptibility pattern is a clue that helps in the empiric treatment. Locally antimicrobial susceptibility rutine study (Kirby Bauer for non invasive strains and E-test for invasive strains) must be performed in HTM medium.

Key words: H. influenzae, Susceptibility testing, Beta-lactamases, Chloramphenicol acetyl transferase.

\section{INTRODUCCIÓN}

El género Haemophilus pertenece a la familia Pasteurellaceae, incluyendo 7 especies $(H$. influenzae, parainfluenzae, ducreyi, haemolyticus, parahaemolyticus, segnis y aphrophilus). Como género se caracteriza por agrupar bacilos Gram negativos pequeños, pleomorfos, que viven en las mucosas del hombre y animales. Para su desarrollo requieren factores de creci- miento $\mathrm{X}$ (hemina) y V (NAD). En nuestro medio, las especies más relevantes por su frecuencia son $H$. influenzae y $H$. parainfluenzae.

Las principales muestras en que se puede aislar Haemophilus son: sangre, líquidos estériles (LCR, articular, pleural, peritoneal y otros), muestras respiratorias altas y bajas (secreción ótica, aspirado de senos paranasales, expectoración, LBA), secreción ocular, secreción nasal y secreción vaginal.

\footnotetext{
${ }^{1}$ Programa de Microbiología, Instituto de Ciencias Biomédicas, Facultad de Medicina, Universidad de Chile.
} 
El transporte de la muestra debe ser realizado inmediatamente después de obtenida, en medio de transporte Amies o Stuart sin refrigerar, puesto que se trata de microorganismos lábiles al ambiente seco y a bajas temperaturas. La siembra de la muestra se debe realizar en placa de agar chocolate enriquecido (con Vitox ${ }^{\circledR}$ o Isovitalex $\left.{ }^{\circledR}\right)$ para lograr un mejor rendimiento, incubando a $37^{\circ} \mathrm{C}$ durante 18 a $24 \mathrm{hrs}$ en atmósfera con $5 \%$ de $\mathrm{CO}_{2}$. En caso de investigar portadores, se debe adicionar a la placa bacitracina, en concentración de $200 \mu \mathrm{g} / \mathrm{ml}$, con el fin de seleccionar Haemophilus e inhibir parte de la flora microbiana acompañante.

\section{Diagnóstico de género y especie}

La primera aproximación diagnóstica se realiza en base a la observación macroscópica de las placas incubadas, donde se pueden observar colonias pequeñas de $\varnothing 0,5-0,8 \mathrm{~mm}$, de coloración gris-verdosa, de olor característico (recuerda el olor de un pañuelo con secreciones). La observación microscópica mediante la tinción de Gram de la colonia permite observar cocobacilos Gram negativos pleomórficos

El diagnóstico de especie se realiza en base al análisis de requerimiento de factores $\mathrm{X}$ y V (Tabla 1). La técnica consiste en preparar una suspensión de la cepa en caldo Mueller Hinton $(\mathrm{MH})$, ajustada a 0,5 de Mc Farland. Siembre con tórula en medio sólido agar tripticasa soya (TSA) o $\mathrm{MH}$, coloque discos o tiras de factores (X, V y XV) e incube a $37^{\circ} \mathrm{C}$ durante 18 a 24 hrs en $5 \% \mathrm{CO}_{2}$. Para la interpretación de los
Tabla 1. Características diferenciales de las distintas especies de Haemophilus

\begin{tabular}{lcc}
\hline Especie & Factores* & Hemólisis \\
\hline H. influenzae & $\mathrm{XV}$ & - \\
H. haemolyticus & $\mathrm{XV}$ & + \\
H. parainfluenzae & $\mathrm{V}$ & - \\
H. parahaemolyticus & $\mathrm{V}$ & + \\
H. ducreyi & $\mathrm{X}$ & - \\
H. segnis & $\mathrm{V}$ & - \\
H. aphrophilus & $\mathrm{V}$ & - \\
H. paraphrophilus & $\mathrm{V}$ & - \\
* Requeridos para su desarrollo in vitro. & \\
\hline
\end{tabular}

resultados se debe considerar positivo el desarrollo de colonias o de un velo en torno a cada factor ensayado.

\section{Criterios de clasificación de H. influenzae:}

Existen diversos criterios de clasificación que permiten la caracterización de $H$. influenzae:

- clínico: origen invasor (sangre, LCR, líquido articular, pericárdico, tejidos blandos, etc) versus no invasor (superficie de mucosas)

- serotipificación de a-f según la composición antigénica de la cápsula.

- biotipificación de I a VIII: basado en pruebas de: indol, ureasa, ornitina decarboxilasa

- subtipificación: en base a proteínas de membrana externa (PMO), se describen 21 subtipos

- análisis de genes CAP (capsulares): se describen 14 patrones de restricción

Tabla 2a. Selección de antimicrobianos primarios a evaluar en cepas de Haemophilus influenzae. Recomendaciones de NCCLS 2001

\begin{tabular}{lcccc}
\hline Antimicrobianos & $\begin{array}{c}\text { Carga del disco } \\
(\boldsymbol{\mu g})\end{array}$ & $\begin{array}{c}\varnothing \text { halo de inhibición (mm) } \\
\text { Susceptibilidad } \\
\text { intermedia }\end{array}$ & $\begin{array}{l}\text { Susceptible } \\
\text { Resistente }\end{array}$ \\
\hline Ampicilina & 10 & $<18$ & $19-21$ & $>22$ \\
Amoxicilina/ácido clavulánico & $20 / 10$ & $<19$ & - & $>20$ \\
Cotrimoxazol (trimetoprim/sulfa) & $1.25 / 23.75$ & $<10$ & $11-15$ & $>16$ \\
Cloranfenicol & 30 & $<25$ & $26-28$ & $>29$ \\
Cefuroxima & 30 & -16 & $17-19$ & $>20$ \\
Cefotaxima & 30 & - & - & $>26$ \\
Meropenem & 10 & - & $>20$ \\
\hline
\end{tabular}


Tabla 2b. Selección de antimicrobianos complementarios a evaluar en cepas de Haemophilus influenzae. Recomendaciones de NCCLS 2001.

\begin{tabular}{lcccc}
\hline Antimicrobianos & $\begin{array}{c}\text { Carga del disco } \\
(\mu \mathrm{g})\end{array}$ & $\begin{array}{c}\varnothing \text { halo de inhibición (mm) } \\
\text { Resistente } \\
\text { Susceptibilidad } \\
\text { intermedia }\end{array}$ & Susceptible \\
\hline Azitromicina & 15 & - & & $>12$ \\
Claritromicina & 15 & $<10$ & $11-12$ & $>13$ \\
Cefaclor & 30 & $<16$ & $17-19$ & $>20$ \\
Ciprofloxacina & 5 & - & - & $>21$ \\
\hline
\end{tabular}

- tipo electroforético, basado en la presencia de aloenzimas.

\section{Estudio de susceptibilidad a antimicrobianos}

Los antimicrobianos a evaluar e informar se mencionan en las Tablas 2a y 2b. Básicamente, hay tres metodologías para abordar el estudio de susceptibilidad en $H$. influenzae: método de difusión con disco (Kirby-Bauer), dilución en caldo o agar para determinar la CIM y detección rápida de enzimas.

\section{Difusión con disco o Kirby-Bauer}

- Preparación del inóculo: consiste en una suspensión directa en caldo, cuidando de obtener una turbidez equivalente a 0,5 de $\mathrm{Mc}$ Farland. Este es un punto considerado crítico.

- El medio recomendado por la NCCLS es el HTM (Haemophilus test medium); sin embargo, por su alto costo, en muchos laboratorios se continúa utilizando medio de agar chocolate, con resultados muy similares a los obtenidos en HTM, especialmente para ampicilina, cloranfenicol y asociaciones de amoxicilina-ácido clavulánico y ampicilinasulbactam. Incubación durante 18 a 24 hrs, a $37^{\circ} \mathrm{C}$ con $5 \% \mathrm{CO}_{2}$

- Respete el número de discos recomendado por placa (ver artículo pág S7), dado que tiende a producir grandes halos.

- Control de calidad con cepas ATCC 4924749766 y Escherichia coli ATCC 35218 (para combinaciones de $\beta$ lactámicos con inhibidor de $\beta$ lactamasas).

\section{Método de dilución: CIM}

Este es el método de referencia recomendado por la NCCLS, reservado para casos especiales y estudios epidemiológicos de resistencia. Consiste en microdilución en caldo HTM, que constituye el gold standard y epsilometría (E-test $\left.{ }^{\circledR}\right)$, como alternativa en situaciones clínicas.

Al igual que en el método de difusión, se debe preparar un inóculo con suspensión directa de colonia, incube a $35^{\circ} \mathrm{C}$ durante $24 \mathrm{hrs} \sin$ $\mathrm{CO}_{2}$.

\section{Detección rápida de enzimas}

- Detección de $\beta$ lactamasa por el método de cefalosporina cromogénica (discos impregnados):

Se humedece el disco con agua estéril, colocando sobre él una asada de colonias. La lectura se realiza en el lapso de 15 segundos a 5 minutos, observando cambio de color para dar la prueba por positiva.

\section{Interpretación:}

$\beta$ lactamasa positivo: resistencia a $\beta$ lactámicos

$\beta$ lactamasa negativo: probablemente susceptible aunque no asegura susceptibilidad, dado que se describe $\sim 1 \%$ de cepas resistentes a ampicilina y que son $\beta$ lactamasa (-), esta resistencia estaría mediada por alteraciones de PBPs.

- Detección rápida de cloranfenicol acetil transferasa (CAT):

Prepare un inóculo Mc Farland 3 de E. coli 
sensible a cloranfenicol. Siembre en placa de TSA.

Coloque sobre esta siembra un disco de papel estéril impregnado con la cepa de Haemophilus a ensayar. Sobre este disco impregnado, coloque un sensidisco de cloranfenicol. Incube a $42^{\circ} \mathrm{C}$ durante 4 a 6 hrs y efectúe la lectura.

\section{Interpretación:}

No hay halo de inhibición en torno a los discos: la cepa incógnita tenía CAT, por lo que se degrada el cloranfenicol del sensidisco y la cepa de E. coli se desarrolla hasta el borde de los discos.

Hay halo de inhibición en torno a los discos: la cepa incógnita es negativa para CAT, por lo que el sensidisco de cloranfenicol permanece intacto y ejerce actividad inhibitoria sobre el inóculo de E. coli sembrado.

\section{Estudio de susceptibilidad a antimicrobianos recomendado para $H$. influenzae según procedencia y tipo de muestra}

\section{Según procedencia:}

Paciente ambulatorio: detección rápida de $\beta$ lactamasa. Informe ampicilina y asociaciones con inhibidores de $\beta$ lactamasa.

Paciente hospitalizado: detección rápida de $\beta$ lactamasa y test de susceptibilidad por difusión.

\section{Según tipo de muestra:}

Muestra de origen invasor: test de susceptibilidad por difusión y detección de $\beta$ lactamasa.

Muestra de origen no invasor: detección de $\beta$ lactamasa.

\section{RESUMEN}

El género Haemophilus comprende un grupo de bacilos Gram negativos de requerimientos fastidiosos. $H$. influenzae tipo $b$, la especie más importante, es un cocobacilo Gram negativo pequeño, que en muestras clínicas aparece pleomórfico. Es una bacteria inmóvil, no esporulada, anaerobia facultativa, que requiere dos factores de crecimiento (X-V) presentes en eritrocitos, los cuales son liberados mediante calor (agar chocolate).

El principal criterio diagnóstico para las infecciones por $H$. influenzae es la tinción de Gram y el aislamiento del microorganismo del sitio de infección. Por ser el Haemophilus muy fastidioso, las muestras deben ser sembradas inmediatamente, en la superficie de un agar chocolate e incubadas en ambiente de $10 \%$ de $\mathrm{Co}_{2}$.

El tratamiento de las infecciones invasoras por Haemophilus tipo b, especialmente meningitis, es una emergencia médica, cualquier retardo en el inicio del tratamiento puede hacer diferencia entre la vida y la muerte, por tanto el conocimiento del patrón de susceptibilidad antimicrobiana de las cepas es clave para ayudar el tratamiento empírico. El estudio de susceptibilidad antimicrobiana de rutina realizado localmente (Kirby Bauer en caso de cepas no invasivas y E-test en invasivas) debe ser realizado en HTM medium.

\section{BIBLIOGRAFÍA}

1.- KONEMAN E W, ALLEN S D, JANDA W M et al. Haemophilus. En Konemam, Diagnostic Microbiology, fourth edition, Philadelphia, J P Lippincott Company, 1992: pp 279-301.

2.- National Committee for Clinical Laboratory Standards. 2001. Performance standards for antimicrobial susceptibility testing; Eleventh Informational Supplement, M100-S11. NCCLS Vol 21, $\mathrm{N}^{\circ} 1$.

3.- LIVERMORE D L, BROWN D F. Detection of $\beta$ lactamase mediated resistance. J Antimicrob Chemother 2001, 48 (Suppl S1): 59-64.

4.- CAMPOS J, GRACÍA TORNEL S, SANFELIU I. Susceptibility studies of multiply resistant $H$. influenzae isolated from pediatric patients and contacts. Antimicrob Agents Chemother, 1984; (2S): 706-9.

5.- CAMPOS J M. Haemophilus. In Murray P R, Baron E J, Pfaller M A, Tenover F C, Yolken R H. (ed). Manual of Clinical Microbiology $\left(7^{\text {th }}\right.$ ed) Washington DC. American Society for Microbiology, 1999: pp 604-13.

6.- CHAPIN K, DOEM G. Selective media for recovery of Haemophilus influenzae from specimens contaminated with upper respiratory tract microbial flora. J Clin Microbiol 1984, 19: 333-7.

7.- JORGENSEN J H. Update on mechanism and prevalence of antimicrobial resistance in Haemophilus influenzae. Clin Infect Dis 1992, 14:1119-23.

Correspondencia a:

Olivia Trucco Aray

E-mail: olivia.trucco@aventis.com 